\title{
Watermelon (Citrullus Vulgaris): An Innovative Plant that accelerates the Healing of Pulpal Wound
}

\author{
${ }^{1}$ Trimurni Abidin, ${ }^{2}$ Harry Agusnar, ${ }^{3} \mathrm{D}$ Dennis
}

\begin{abstract}
Introduction: Pulpal wounds are the result of injuries like iatrogenic procedures or traumatic to the pulp of teeth that disrupt the pulp. Healing of a wound is a complex and protected process of tissue repair and remodeling in response to injury. In tooth with pulpal exposure, the healing is to reconstitute the lost continuum at the pulp-dentin border in order to effectively restore the lost dentin structure.
\end{abstract}

Materials and methods: This study was conducted to investigate the phytoconstituents derived from watermelon (Citrullus vulgaris) and to analyze the particle size of watermelon frost.

Results: Watermelon, the same as the other plants, contained triterpenoid/steroid, alkaloid, flavonoid, glikosida, and saponin, while the mean particle size is $12.34 \mu \mathrm{m}$. It is seen that watermelon has the ability to promote wound healing as a result of injury.

Conclusion: Watermelon can be developed as a plant that has a therapeutic effect for tissue engineering in dentistry, especially in the field of conservation of teeth to maintain the health of dentin-pulp complex.

Keywords: Healing, Pulpal wound, Watermelon.

How to cite this article: Abidin T, Agusnar H, Dennis D. Watermelon (Citrullus Vulgaris): An Innovative Plant that accelerates the Healing of Pulpal Wound. World J Dent 2016;7(3):155-161.

Source of support: This research was supported by Indonesia Directorate of Higher Education (Grant number 109/WN 5. 2.3.1/PPM/SP/2015).

Conflict of interest: None

\section{INTRODUCTION}

Treatment of vital dental pulp is one of the dental care in the field of conservation that aims to maintain pulp vitality injured as a result of mechanical or iatrogenic trauma and diagnosis of reversible pulpitis. When the pulp is injured as a result of injury, damage will occur

\footnotetext{
${ }^{1-3}$ Faculty

${ }^{1,3}$ Department of Conservative Dentistry, Faculty of Dentistry University of Sumatera Utara, Medan, Sumatera Utara, Indonesia

${ }^{2}$ Department of Chemistry, Faculty of Mathematics and Natural Sciences, University of Sumatera Utara, Medan, Sumatera Utara, Indonesia

Corresponding Author: D Dennis, Faculty, Department of Conservative Dentistry, Faculty of Dentistry, University of Sumatera Utara, Medan, Sumatera Utara, Indonesia, Phone: +628126555068, e-mail: dennis_dionisius@yahoo.co.uk
}

at odontoblast cells located in peripheral pulp layer, subodontoblastic, so it needs a biomaterial that can stimulate healing and stimulate the pulp cells to repair the injured area with the formation of reparative dentin. ${ }^{1}$

In the field of conservative dentistry (endodontics), the use of the materials to cover wounded pulp, including calcium hydroxide, which is still the gold standard, mineral trioxide aggregate (MTA), biodentin all of which are nonbiological materials. With the development of tissue engineering in the conservation of the tooth, especially in the field of Regenerative Endodontics, it has been developed as a variety of biomaterials, namely various growth factors, such as bone morphogenetic protein, transforming growth factor beta, colony stimulating factor, epidermal growth factor, fibroblast growth factor, platelet-derived growth factor, transforming growth factor alpha, and nerve growth factor. ${ }^{1}$ But all of this biomaterial are still an expensive and imported goods in Indonesia.

Currently, many studies were carried out in Indonesia to look for a replacement of imported biomaterials by using the basic ingredients of herbs or that can be obtained from the natural environment in Indonesia. World Health Organization (WHO) has recommended the use of traditional medicine, including herbal plants in the maintenance of public health, prevention and treatment of diseases, especially chronic diseases, degenerative diseases, and also for cancer. The Government of Indonesia has framed a National Program Policy for the development of natural drugs to make Indonesia the world's number one producer of natural drugs in the natural-based drug industry (World First Herbal Medicine Country) by 2020.

Watermelon (Citrullus vulgaris), which probably originated in Africa, belongs to the Cucurbitaceae family that includes cucumbers, squash, and gourds. The first records of its cultivation in the Mediterranean region date to some 3,000 years ago. ${ }^{2,3}$ Watermelon is a popular fruit, which is usually consumed fresh directly in slices or diced and mixed with other fruit (fruit salad). Additionally, it can be processed as juice, jam, or pickled rind, and the seeds (from seed cultivars) are also consumed. ${ }^{3}$ Medicinally, watermelons are mild diuretic, being effective in the treatment of dropsy and renal stones, as well as reducing hypertension. ${ }^{4}$ It also helps to prevent erectile dysfunction, acts as an antioxidant, and is used to 
treat enlarged liver and jaundice. It can also be used as a natural alternative to chemical treatment for giardiasis. 5,6

Watermelon biomass can be categorized into three main components: The flesh, seed, and rind. The flesh constitutes approximately $68 \%$ of total weight, the rind approximately $30 \%$, and the seeds approximately $2 \%{ }^{7}$ The compositions of the flesh, seed, and rind vary considerably. Watermelon flesh contains over $90 \%$ water, providing a source of liquid in arid regions but little protein or fat. The total sugar content is around $7 \%$ with some carotenes and a vitamin C content of $8 \mathrm{mg} / 100 \mathrm{gm} .^{2}$

Watermelon frost is a traditional medicine that has been used for sore teeth, swollen gums, and burns. Watermelon frost was obtained from watermelon (Citrullus vulgaris) and processed by Glauber's salt (sodium sulfate decahydrate). Watermelon frost was reported to have oral antibacterial properties that cause tooth caries namely Streptococcus mutans. ${ }^{8}$ In a research Trimurni and Dennis ${ }^{9}$ reported that watermelon frost is able to reduce the levels of PGE2 on teeth with irreversible pulpitis. Dennis ${ }^{10}$ conducted an in vivo study in the teeth of Macaca fascicularis and showed the effect of the decrease in expression of substance $P$ in pulp tissue that undergoes reversible pulpitis, which is mechanically induced after being applied with watermelon frost.

Although, previous studies had examined the content of watermelon, but until now, the content of watermelon that plays a role in reducing tissue inflammation when used topically, especially on tissue injured dental pulp through phytochemicals, has not been known, and analysis of frost obtained from watermelon so that it can be used as a topical dressing in dental pulp which undergoes reversible pulpitis due to injury is also not done. ${ }^{7,11}$

\section{MATERIALS AND METHODS}

This research is an experimental study aimed to identify and specify the content of watermelon with phytochemical screening, which is a preliminary test in determining the class of secondary metabolites and compounds that have biological activity of the plant.
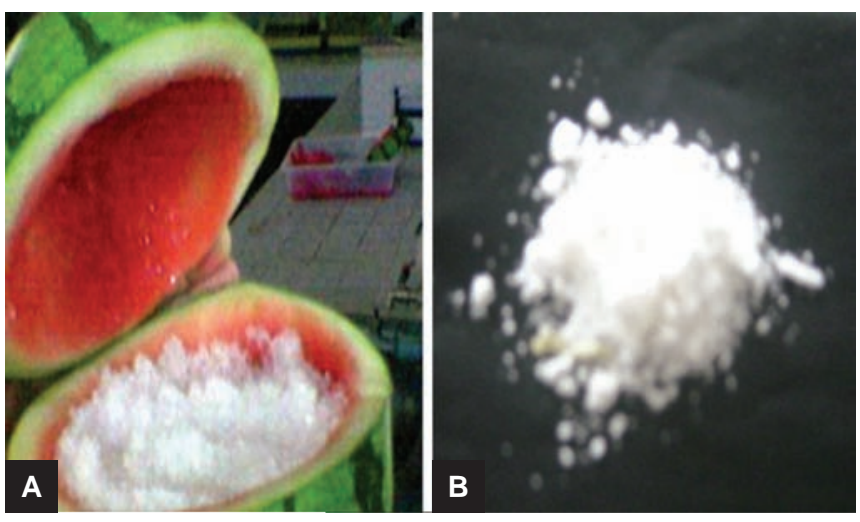

Figs $1 \mathrm{~A}$ and $\mathrm{B}$ : Watermelon by Glauber's salt to obtain the frost

\section{Preparation of Trial Materials}

Watermelon is obtained from Tanjung Morawa Medan Sumatera Utara Indonesia, where sampling is done purposively, i.e., without comparing elsewhere. The sample used was a fresh watermelon containing seeds.

\section{Sample Processing}

\section{Processing Watermelon into Crystals (Frosting)}

Watermelon was washed on its rind and a small hole was made in the middle for a Glauber's salt to be added, then covered again, and left in the refrigerator. After being left about for 2 weeks, it will form an amorphous crystal (frost) (Figs 1A and B).

\section{Processing of Samples for the Analysis of the Content of Secondary Metabolites}

Watermelon is washed, then halved, and its contents red and white are separated from the flesh (flesh), and from each content the juice taken. Each extract was evaporated with water bath and viscous extract was obtained. Then each flesh was dried in the refrigerator (Fig. 2).

\section{Phytochemical Screening}

\section{Examination of Steroid/Triterpenoids}

A total of $1 \mathrm{gm}$ of sample was macerated with $20 \mathrm{~mL}$ of ether for 2 hours and filtered. The filtrate evaporated with evaporator cup and the remainder was added 20 drops of acetic acid anhydride and 1 drop of concentrated sulfuric acid (reagent Liebermann-Burchard). When formed purple or red color changed to blue green, which indicates steroid/triterpenoids.

\section{Test of Alkaloids}

To a total of $0.5 \mathrm{gm}$ of sample, add $1 \mathrm{~mL}$ of $2 \mathrm{~N}$ hydrochloric acid and $9 \mathrm{~mL}$ of distilled water, heated on a water

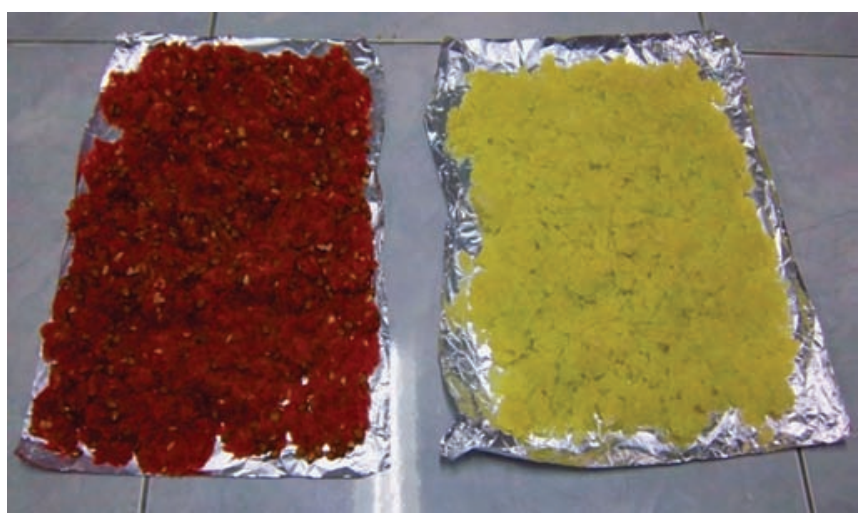

Fig. 2: Residue of watermelon and white flesh after extraction 
bath for 2 minutes, cooled, and filtered. The filtrate used to test alkaloids is as follows:

- The filtrate as much as 3 drops added with 2 drops of reagent solution to form a precipitate Mayer-colored white or yellow.

- The filtrate as much as 3 drops along with 2 drops of reagent solution Bouchardat will form a precipitate brown to blackish.

- The filtrate as much as 3 drops along with 2 drops of reagent solution Dragendorff will form a precipitate of red or orange. Positive alkaloids sediments or turbidity was shown with at least two of the three experiments above.

\section{Test of Flavonoids}

A total of $10 \mathrm{gm}$ of sample was added to $10 \mathrm{~mL}$ of hot water, boiled for 5 minutes, and filtered hot; then $5 \mathrm{~mL}$ of filtrate was added with $0.1 \mathrm{gm}$ of magnesium powder and $1 \mathrm{~mL}$ of concentrated hydrochloric acid and $2 \mathrm{~mL}$ of amyl alcohol, shaken, and allowed to separate. Flavonoids positive was shown with red, yellow, or orange in the lining of amyl alcohol.

\section{Examination of Glycosides}

A total of $3 \mathrm{gm}$ sample was filtered with $30 \mathrm{~mL}$ of $96 \%$ ethanol mixture with water $(7: 3)$, refluxed for 10 minutes, cooled, and filtered. Then to $20 \mathrm{~mL}$ of the filtrate, $25 \mathrm{~mL}$ of distilled water and $25 \mathrm{~mL}$ of lead (II) acetate $0.4 \mathrm{M}$ was added, shaken, allowed to stand for 5 minutes, and then filtered. The filtrate was filtered with $20 \mathrm{~mL}$ of a mixture of chloroform and isopropanol (in the ratio 3:2) and repeated three times. Set of water extract is evaporated at a temperature no higher than $50^{\circ} \mathrm{C}$. The remainder is dissolved in $2 \mathrm{~mL}$ of methanol. The remaining solution is used for the experiment as follows: Namely, as many as $0.1 \mathrm{~mL}$ of solution inserted into the tube and evaporated over a water bath. To the residue, $2 \mathrm{~mL}$ of water and 5 drops of Molish reagent were added. Then slowly $2 \mathrm{~mL}$ of concentrated sulfuric acid was added through the tube wall; a purple color ring formed at the boundary between the two fluids showed the sugar bond.

\section{Saponin Examination}

Foam test: A total of $0.5 \mathrm{gm}$ of sample is introduced into the reaction tube. Add $10 \mathrm{~mL}$ of hot distilled water, then cool and shake vigorously for 10 seconds. The presence of saponins was shown by the formation of a stable froth for not less than 10 minutes as high as 1 to $10 \mathrm{~cm}$ and with the addition of 1 to 2 drops of hydrochloric acid, the foam did not disappear.

\section{The Color of the Reagent Test using Liebermann- Burchard (LB)}

A total of $0.5 \mathrm{gm}$ of sample was added to $10 \mathrm{~mL}$ of ethanol. Then on addition of $2 \mathrm{~N}$ hydrochloric acid, the solution was refluxed for 10 minutes and filtered hot. The filtrate was diluted with $10 \mathrm{~mL}$ of distilled water. After cooling $10 \mathrm{~mL}$ of $\mathrm{n}$-hexane was added, then shaken, and allowed to separate. n-Hexane layer was taken and evaporated in the vaporizer cup. To the residual, 20 drops of acetic acid anhydride and 1 drop of concentrated sulfuric acid (reagent LB) were added. Positive result of saponin was shown in green, blue, red, pink, or purple color.

\section{Tannin Examination}

A total of 0.5 gm of sample was mixed with $10 \mathrm{~mL}$ of distilled water and then filtered. The filtrate was diluted with water until colorless. A solution of $2 \mathrm{~mL}$ was taken and 1 to 2 drops of reagent were added with iron (III) chloride $1 \%$. If there is a blue or black color, then it indicates the presence of tannins.

\section{Examination of Anthraquinone}

A total of $0.2 \mathrm{gm}$ of sample was taken and $5 \mathrm{~mL}$ of $2 \mathrm{~N}$ sulfuric acid was added and heated briefly. On cooling add $10 \mathrm{~mL}$ of benzene, shake it well, and allow to stand. Benzene layer was separated and filtered. Then shake it with $2 \mathrm{~mL}$ of $2 \mathrm{~N}$ sodium hydroxide and allow to stand. Red-colored water layer and a layer of colorless benzene showed anthraquinone.

\section{Particle Size Analysis (PSA)}

\section{Measuring Method with PSA}

Particle size analysis measurement was performed to measure the particle size range of 2 to $7000 \mathrm{~nm}$ by using the principle of dynamic motion light scattering and brown. The particle size is calculated based on the correlation function of the Stokes-Einstein and Brownian motion specified as translational diffusion coefficient. Brown ground speed is influenced by the size, viscosity, cumulant, and Laplace methods, where each system produced a size distribution depending on the intensity, number, and volume.

\section{RESULTS AND DISCUSSION}

\section{Results Crystals (Frosting)}

Glauber's salt is added to the results crystals (frost) obtained from a watermelon weighing 3 to $4 \mathrm{~kg}$. It will give 2 to $5 \mathrm{gm}$ frost (Figs $3 \mathrm{~A}$ and $\mathrm{B}$ ). 


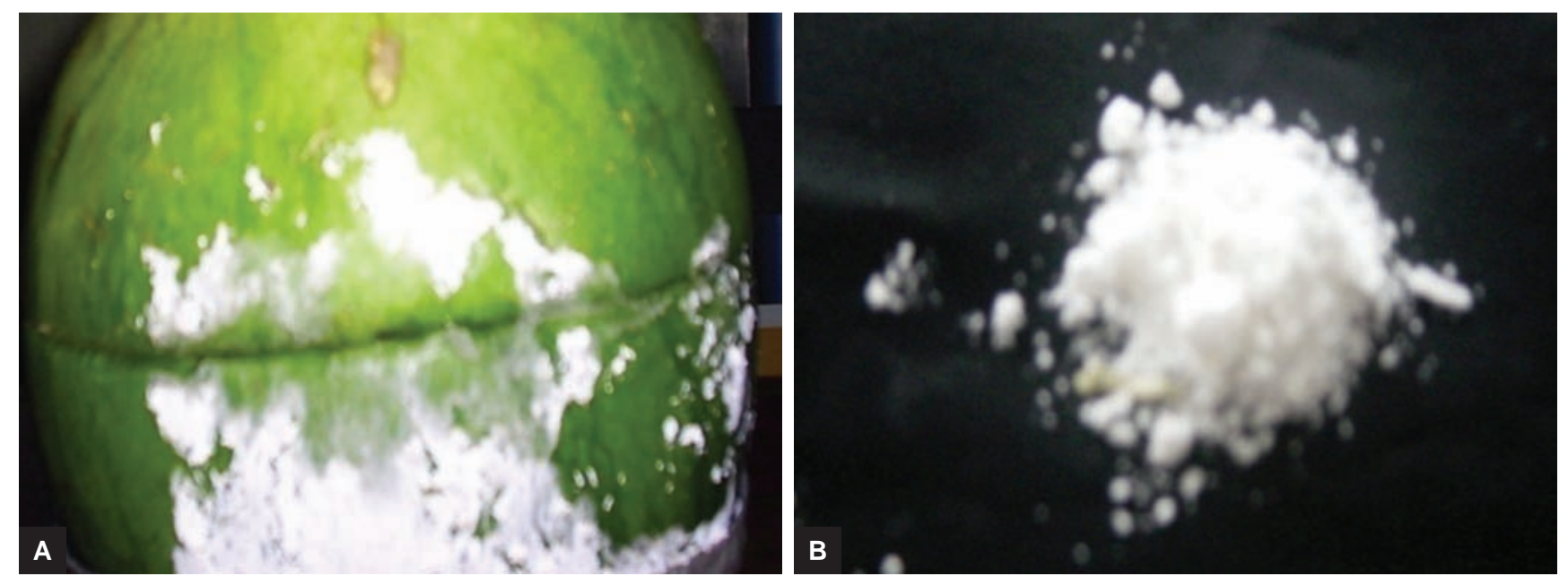

Figs $3 \mathrm{~A}$ and $\mathrm{B}$ : Watermelon frost

\section{Screening Examination Results of Phytochemicals of Watermelon}

The results of phytochemical analysis of watermelon (Citrullus vulgaris) can be seen in Table 1 and the image analysis of phytochemical screening can be seen in Figures $4 \mathrm{~A}$ to $\mathrm{E}$.

The phytochemical screening results in Table 1 show that the class of secondary metabolites contained in the red flesh of watermelon are triterpenoid/steroids,
Table 1: The result of watermelon screening from its red and white flesh

\begin{tabular}{lll}
\hline & \multicolumn{2}{c}{ Watermelon extract } \\
\cline { 2 - 3 } Screening & Red color $(A)$ & White color $(B)$ \\
\hline Tritepenoid/steroid & + & + \\
Alkaloid & + & + \\
Flavonoid & + & - \\
Glycoside & + & + \\
Saponin & + & + \\
Tanin & + & - \\
\hline
\end{tabular}

(+): Positive content; (-): No content
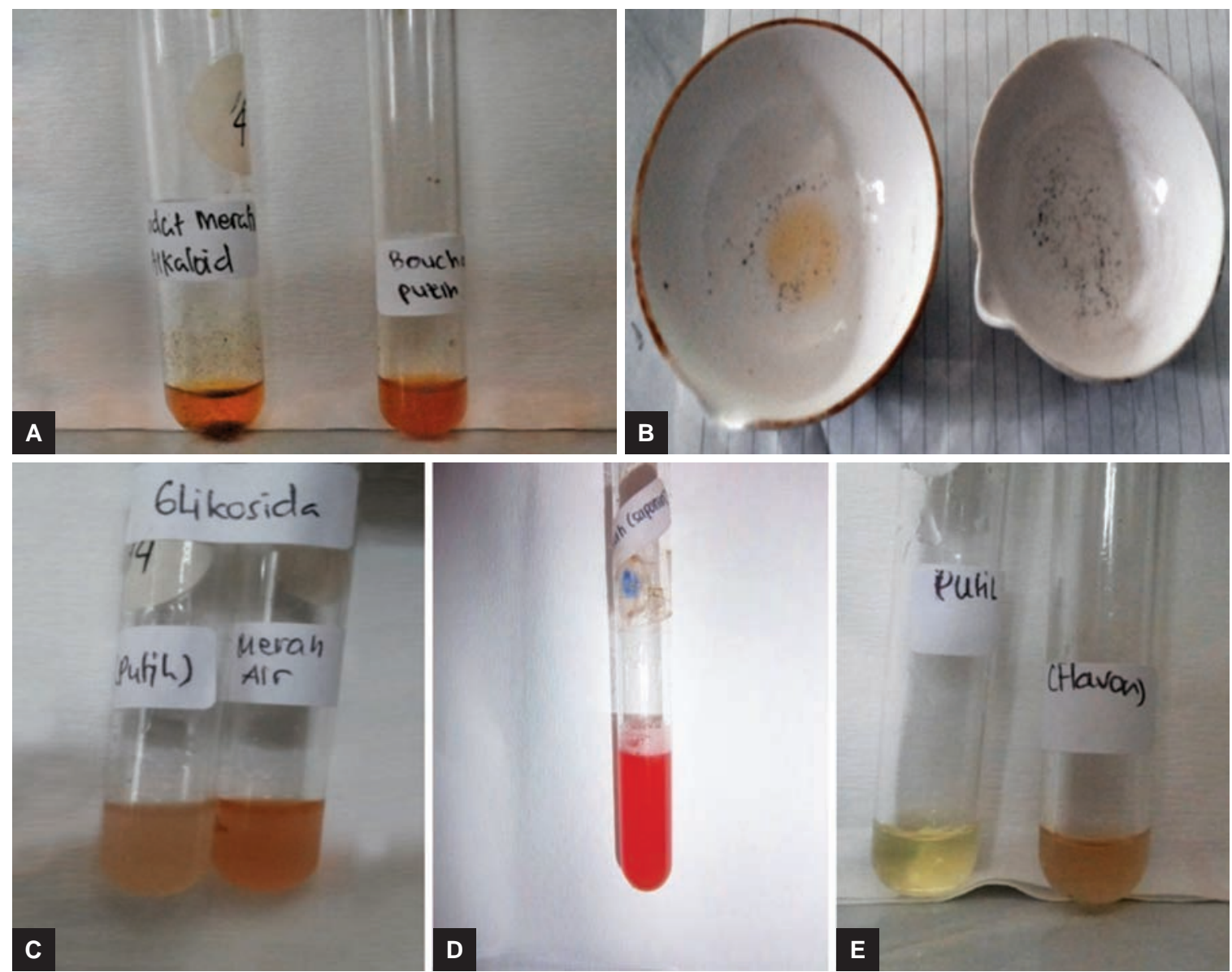

Figs 4A to E: (A) Alkaloid; (B) flavonoid; (C) glikosida; (D) saponin; and (E) tannin 
alkaloids, flavonoids, glycosides, saponins, and tannins, while flavonoids and tannins were not found in its white flesh juice.

\section{Results of Phytochemical Screening}

The watermelon juice added to the LiebermannBurchard reagent gave positive results in red, purple color, and Dragendorff reagent addition gave a brownish color. A reagent, Bouchardat gave brownish red color, while the reagent Mayer formed the white turbidity and sediment. This suggests the existence of alkaloid compounds in watermelon frost. The addition of $\mathrm{Mg}$ powder and $\mathrm{Zn}$ powder with concentrated hydrochloric acid gives a red color, indicating flavonoid compounds (Figs 4A and B).

\section{Examination of Glycoside}

With the addition of $2 \mathrm{~mL}$ of water, 5 drops of reagent Molish, then $2 \mathrm{~mL}$ of concentrated sulfuric acid added carefully formed purple rings, which confirmed the existence of the compound glycoside with further addition of Fehling.

Fehling A and B added together showed the formation of many brick red precipitates. Watermelon juice after being added with $10 \mathrm{~mL}$ of distilled water and shaken vigorously, heat generating froth as high as $1 \mathrm{~cm}$ appeared with the addition of $2 \mathrm{~N} \mathrm{HCl}$, as much as 1 drop, indicating the presence of compound saponin. After the extract refluxed with $2 \mathrm{~N}$ hydrochloric acid and distracted with n-hexane, the extracts evaporate to dryness. On addition of Liebermann-Burchard reagent gave a positive result of the saponin presence. The addition of $1 \% \mathrm{FeCl}_{3}$ gives green color, indicating tannin compounds (Figs 4C to E).
From the results of the phytochemical contents of watermelon it was found that the most bioactive elements found in red flesh are triterpenoids/steroids, alkaloids, flavonoids, glycosides, saponin, and tannins. In this case, it is necessary to know whether there are differences in the contents of red flesh watermelon and watermelon frost. By knowing the secondary metabolites of watermelon frost, they can be tested by thin layer chromatography and paper chromatography using a variety of mobile phase and stains. Glauber's salt is placed in the red watermelon flesh. After some time it will emerge frost, indicating that the flesh of red watermelon interacts with white flesh. Thin layer chromatography results would show the same content of bioactive elements.

\section{Results of Particle Size Analysis}

The result of watermelon-frost PSA is ranging from $0.375 \mu \mathrm{m}$ to sized estimated $948.3 \mu \mathrm{m}$ (Graph 1$)$. The mean particle size of watermelon frost is $12.34 \mu \mathrm{m}$.

Wound healing is a dynamic process consisting of four continuous, overlapping, and precisely programmed phases. The events of each phase must happen in a precise and regulated manner. It is the interaction of a complex cascade of cellular and biochemical actions that leads to the restoration of structural and functional integrity with regain of strength of injured tissue. It involves continuous cell-cell interaction and cell-cell matrix interactions that allow the process to proceed in different overlapping phases and processes include inflammation, wound contraction, re-epithelialization, tissue remodeling, and formation of granulation tissue with angiogenesis. ${ }^{12,13}$ Wound healing of tissue damage involves the following events: (1) rapid hemostasis; (2) appropriate inflammation; (3) mesenchymal cell differentiation, proliferation and migration to the wound site; (4) suitable angiogenesis; (5) prompt re-epithelialization (re-growth of epithelial

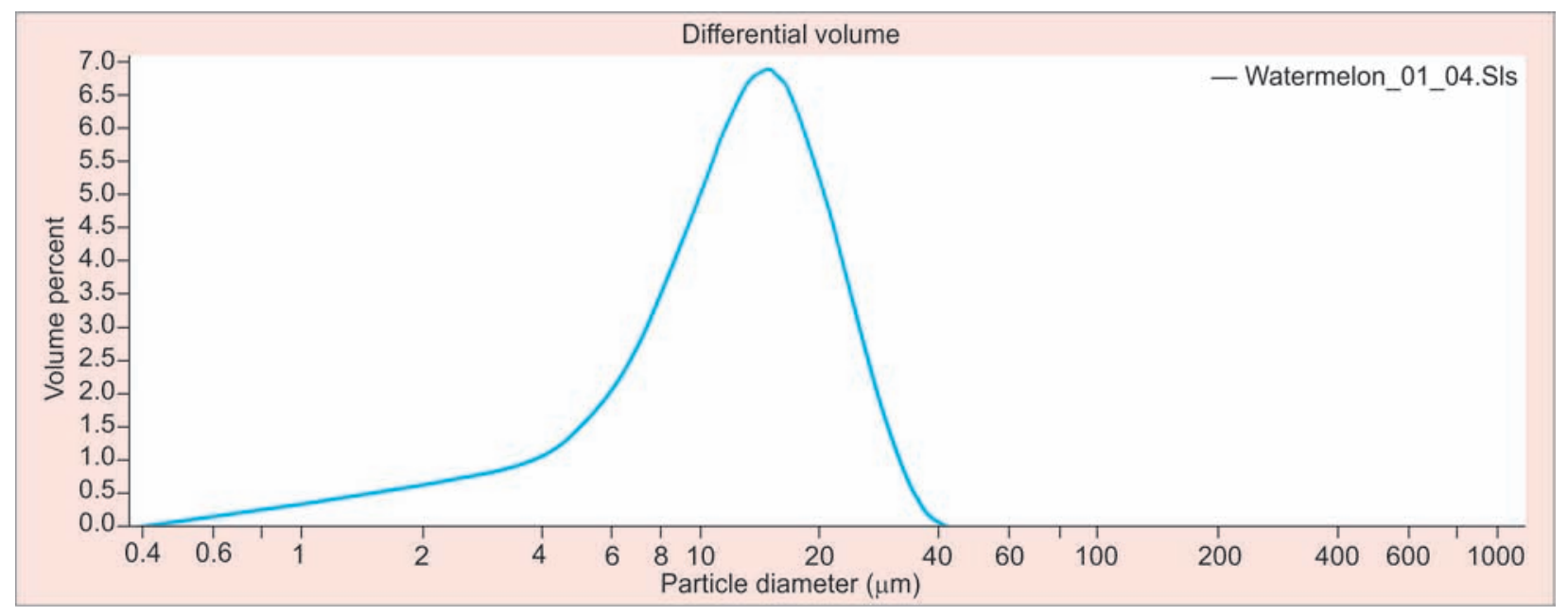

Graph 1: Particle size of watermelon frost 
tissue over the wound surface); and (6) proper synthesis, cross-linking, and alignment of collagen to provide strength to the healing tissue. ${ }^{14}$

In the dental pulp tissue healing, injury is expected to be the regeneration of the dentin-pulp complex. It is systematically considered in combination with the biological phenomenon of tertiary dentinogenesis and not as therapeutic goal in itself. The ultimate goal of a regenerative pulp treatment strategy in pulp exposure due to iatrogenic procedures is to reconstitute the lost continuum at the pulp-dentin border in order to effectively oppose pulp contamination with oral bacteria for a long period of time. The optimal end result of a reasonable therapeutic application in pulp exposure might be the induction of primary or tertiary dentin formation. ${ }^{15}$

Dentin contains many proteins capable of stimulating tissue response. Demineralization of dental tissues following the application of cavity etching agents or restorative materials can lead to realization of growth factors. Therapeutic effect of $\mathrm{Ca}(\mathrm{OH})_{2}$ and MTA may be due to their extraction of growth factors from the dentin matrix. Once released these growth factors may play key roles in signaling many of the events of tertiary dentinogenesis, a response of pulpo-dentin repair. ${ }^{1}$ Growth factors are proteins that bind to receptor and induce cellular proliferation and differentiation. Growth factors are important in cellular signaling for odontoblast, the cell of the pulp, differentiation, and stimulation of dentin matrix secretion, especially those of the transforming growth factor beta family. ${ }^{1,15}$ These growth factors are secreted by odontoblast and deposited within the dentin matrix, where they remain protected in an active from through interaction with other components of the dentin matrix. The addition of purified dentin protein fractions has stimulated an increase in tertiary dentin matrix secretion. ${ }^{1,16}$

Tannins act as free radical scavenger; meanwhile triterpenoids and flavonoids promote wound healing due to their astringent and antimicrobial property. Saponins due to their antioxidant and antimicrobial activity appear to be responsible for wound contraction and elevated rate of epithelialization. Flavonoid derivative has been considered as the main primary biologically active component. It is also a well-known plant compound that inhibits bacterial and fungal growth, reduces the free radicals, and regulates the immune response, suggesting that this component has antibacterial, anti-inflammatory, and immuno-regulatory properties. ${ }^{13,17,18}$ Flavonoids also possess potent antioxidant and free radical-scavenging effect, enhancing the level of antioxidant enzymes in granuloma tissue. ${ }^{19}$ Sterols and polyphenols are also responsible for wound healing due to free radical-scavenging and antioxidant activity, which is known to reduce lipid peroxidation and thereby, reduce cell necrosis and improve angiogenesis. ${ }^{13}$ The therapeutic use of flavonoids in dentistry has been applied as a capping agent in direct pulp capping treatment. ${ }^{17}$

Novel delivery vehicles generated through nanotechnology are raising the novel and promising prospect for controlled and sustained drug delivery across the impenetrable tissue barrier and are a magnificent clinical application of technology for wound management. Particles of $500 \mathrm{~nm}$ size or smaller exhibit a host of unique properties that are superior to their bulk material counterparts. ${ }^{13}$ Particle size analysis of watermelon frost in this study showed $12.34 \mu \mathrm{m}$ particle size that can be processed into nanoscale, thus becoming a material that can be developed in an open pulp tissue treatment as a result of mechanical injury. Small size is a necessary feature, but other properties are needed for nanomaterials to achieve efficacy as a topical delivery vehicle.

Seeing the content of watermelon, it can be said that the watermelon extract is very promising in the treatment of dental pulp tissue that is open due to injury. Christian and Trimurni research $(2006)^{8}$ showed that watermelon frost could inhibit $S$. mutans that damaged the teeth. Furthermore, Dennis $\mathrm{C}^{10}$ research also showed the ability of watermelon frost to relieve pain in teeth with pulp inflammation by decreasing PGE2 (2006) and substance P (2014) that cause tooth pain. It should be further investigated to identify other components contained by watermelon, so that, it can be developed as a biomaterial that could be used in the treatment of pulpal tissue disease. In conclusion, it seems that watermelon can be developed as a plant that has therapeutic effect for tissue engineering in dentistry, especially in the field of conservation of teeth to maintain pulpo-dentinal complex.

\section{ACKNOWLEDGMENT}

Authors are thankful to Dr. Dra. Marline Nainggolan, MS, Apt from Faculty of Pharmacy, University of Sumatera Utara for her help in the phytochemical analysis.

\section{REFERENCES}

1. Murray PE, Garcia-Godoy F. Stem cells and regeneration of the pulpo-dentine complex. In: Hargreves K, Goodes HE, Tay FR, editors. Seltzer and Bender's dental pulp. 2nd ed. Chicago (IL): Quintessence Publ. Co. Inc; 2012.

2. Vaughan J, Geissler C. The new Oxford book of food plants. Oxford: Oxford University Press; 2009.

3. Helstosky C. Food culture in the Mediterranean. Westport (CT): Greenwood Press; 2009.

4. Figueroa A, Sanches-Gonzales MA, Wong A, Arjmandi BH. Watermelon extract supplementation reduces ankle blood pressure and carotid augmentation index in obese of adults 
with prehypertension or hypertension. Am J Hypertens 2012 Jun:25(6):640-643.

5. Erukainure OL, Oke OV, Daramola AO, Adenekan SO, Umanhonien EE. Improvement of the biochemical properties of watermelon rinds subjected to Saccharomyces cerevisiae solid media fermentation. Pak J Nutr 2010;9(8):806-809.

6. Hasan LEA, Koko WS, Osman EBE, Dahab MM, Sirat HM. In vitro antigiardial activity of Citrullus lanatus Var. citroides extracts and cucurbitacis isolated compounds. J Med Plants Res 2011 Aug;5(15):3338-3346.

7. Campbell M. Extraction of pectin from watermelon rind. Stillwater (OK): Oklahoma State University; 2006.

8. Christian A, Trimurni A. The antibacterial effect watermelon frost on streptococcus mutans (in vitro study). Dentsplay Award 2006, Jakarta.

9. Dennis C, Trimurni A. Effect of watermelon frost on PGE2 in inflamed pulp tissue (in vitro study). Dent J 2009;42(2):82-85.

10. Dennis C. Effect of watermelon frost on the expression of substance $-\mathrm{P}$ and alkaline phosphatase in reversible pulpitis of Macaca fascicularis (in vivo study) [thesis]. Specialist Program of Conservative Dentistry, Faculty of Dentistry, University Sumatera Utara, Indonesia; 2014.

11. Raedah A. Characterization of phenolic compounds in highly-consumed vegetable matrices by using advanced analytical techniques [doctoral thesis]. Faculty of Sciences, University of Granada; 2013.

12. Guo S, DiPietro LA. Factor affecting wound healing. J Dent Res 2010 Mar;89(3):219-229.

13. Thakur R, Jain N, Pathak R, Sandhi SS. Practices in wound healing studies of plants. Evid Based Compliment Alternat Med 2011;2011:438056.

14. Gosain A, DiPietro LA. Aging and wound healing. World J Surg 2004 Mar;28(3):321-326.

15. Tziafas D. Dentinogenic potential of the dental pulp: facts and hypothesis. Endod Top 2010;17(1):42-64.

16. Smith AJ, Lumley PJ, Tomson PL, Cooper PR. Dental regeneration and materials - a partnership. Clin Oral Invest 2008 Jun;12(2):103-108.

17. Sabir A. Inflammatory response on rat's dental pulp following application of propolis - derived flavonoid extract. Dentika Dent J 2007:12(1):34-37.

18. Ahuja V, Ahuja A. Apitherapy - a sweet approach to dental disease. Part II: propolis. J Acad Adv Dent Res 2011 May;2(2):1-8.

19. Shenoy C, Patil MB, Kumar R, Patil S. Preliminary phytochemical investigation and wound healing activity of Alium cepa Linn (Liliaceae). Int J Pharm Pharm Sci 2009 Jul-Sep;2(2):167-175. 